\title{
Metabolic alteration in tumorigenesis
}

\author{
YANG Hui $^{1}$, XIONG Yue ${ }^{1,2^{*}} \&$ GUAN KunLiang ${ }^{1,3^{*}}$ \\ ${ }^{1}$ Molecular and Cell Biology Lab, Institutes of Biomedical Sciences, Shanghai Medical College; School of Life Sciences, \\ Fudan University, Shanghai 200032, China; \\ ${ }^{2}$ Department of Biochemistry and Biophysics and Lineberger Comprehensive Cancer Center, University of \\ North Carolina at Chapel Hill, North Carolina 27599, USA; \\ ${ }^{3}$ Department of Pharmacology and Moores Cancer Center, University of California San Diego, La Jolla, CA 92093, USA
}

Received July 16, 2013; accepted August 7, 2013; published online October 9, 2013

\begin{abstract}
Altered metabolism in cancer was first discovered by Otto Warburg early last century. Although the Warburg Effect has been widely used in tumor detection, relatively little progress had been made in mechanistic understanding of cancer metabolism in the subsequent eight decades. Genetic studies have recently identified mutations in human cancer targeting multiple enzymes involved in intermediate metabolism. One emerging mechanism common to these mutant enzymes is the accumulation of a metabolite that alters the epigenetic control.
\end{abstract}

metabolite, epigenetic, tumorigenesis

Citation: Yang H, Xiong Y, Guan K L. Metabolic alteration in tumorigenesis. Sci China Life Sci, 2013, 56: 1067-1075, doi: 10.1007/s11427-013-4549-2

Otto Warburg $[1,2]$ first discovered that cancer cells displayed enhanced glucose uptake and aerobic glycolysis, a phenomenon often referred as the Warburg Effect nowadays. Although the mechanism underlying the Warburg Effect is still not fully understood, increased uptake of glucose provides the basis to exploit its clinical application by ${ }^{18} \mathrm{~F}$-deoxyglucose positron emission tomography (PET) for tumor detection [3,4]. Decades after the Warburg Effect was discovered, the mechanistic insights of how metabolic alterations contribute to tumorigenesis are just emerging. Recent studies have revealed that eight metabolic genes, $F H$, SDHA, $S D H B, S D H C, S D H D, S D H A F 2, I D H 1$ and $I D H 2$, encoding for subunits of four different metabolic enzymes, fumarate hydratase $(\mathrm{FH})$, succinate dehydrogenase ( $\mathrm{SDH})$, and isocitrate dehydrogenase 1 and 2 (IDH1 and IDH2), were mutated in a number of human cancers [5]. These findings provide compelling genetic evidence supporting the notion that altered metabolism contributes to, as opposed to the conse-

*Corresponding author (email: yxiong@email.unc.edu; kuguan@ucsd.edu) quence of, tumorigenesis. Here, we first briefly discuss how metabolism is reprogrammed to support cancer cell proliferation. We then focus on one emerging mechanism that is common to the mutations targeting all four metabolic enzymes in accumulating a metabolite to alter the epigenetic modifications in human cancer.

\section{Cancer cells reprogram metabolism for pro- liferation}

Cancer cells require much more energy, reductive power, and intermediates as precursors than normal cells for the biosynthesis of macromolecules to support the high rate of cell growth and proliferation. This was what Otto Warburg has observed more than 80 years ago as perhaps the first phenotype of tumor cells that they consume glucose at a surprisingly high rate compared with normal cells, and accumulate a significant amount of lactate rather than oxidiz- 
ing glucose completely to water and $\mathrm{CO}_{2}[1,2,6,7]$. In other words, the tumor cells appear to favor the anaerobic metabolism even in the presence of normal oxygen supply.

The high rate of glycolysis presumably provides several advantages for cell proliferation. First, increased glucose uptake allows cells to produce sufficient ATP. Because of the high rate of glycolytic activity, the percent of ATP produced from glycolysis could exceed that produced from oxidative phosphorylation [1]. Second and perhaps more importantly, glycolysis, as opposed to completely metabolism of glucose to water and $\mathrm{CO}_{2}$ after TCA and oxidative phosphorylation, provides many intermediates for cell biosynthesis, including glycerol for lipids, ribose-5-phosphate for nucleotides, nonessential amino acids, and so on. Thus, high glucose uptake benefits the cancer cells both in bioenergetics and biosynthesis.

In addition to glucose, increased glutamine uptake is another tumor-specific metabolic alteration [8,9]. Glutamine is first converted to glutamate by glutaminase and then deaminated to produce $\alpha$-ketoglutarate ( $\alpha-\mathrm{KG}$ ) to enter the TCA cycle by either a transaminase or glutamate dehydrogenase. Glutamine plays several important roles in supporting cell growth and proliferation. First, glutamine serves as a carbon source and a nitrogen donor for energy production and biosynthesis. It was reported that glutamine could fully sustain the oxidative TCA cycle for energy production, even in the absence of glucose [10]. In proliferating cells, glutamine could contribute to citrate production and de novo lipogenesis through the reductive carboxylation of $\alpha-\mathrm{KG}$ by isocitrate dehydrogenase under hypoxia and glucose starvation conditions [10-13]. Second, glutamine serves as an activator of mTOR1, which is a central cell growth controller, to promote cell growth. Increased intracellular glutamine could be used to facilitate the import of essential amino acids $[14,15]$. Third, glutamine takes part in the synthesis of glutathione, an endogenous antioxidant, to maintain the cellular redox homeostasis. Stimulation of glutamine uptake by p53 was shown to result in an increased ratio of reduced to oxidized glutathione (GSH/GSSG) and protect the cells against oxidative stress $[16,17]$.

\section{Mutations of metabolic genes in cancer}

\subsection{Mutations of $S D H$ genes cause the accumulation of succinate}

Succinate dehydrogenase (SDH) is involved in the TCA cycle and also participates in the electron transport chain as the respiratory complex II. SDH is composed of four subunits, which are named SDHA, SDHB, SDHC and SDHD, and is activated by SDH5 (also named SDHAF2) [18]. SDH catalyzes the conversion of succinate to fumarate with the concomitant reduction of ubiquinone to ubiquinol. The $S D H$ gene was the first metabolic gene discovered to be mutated in human cancer, specifically in paragangliomas $[19,20]$.
$S D H$ mutations were also found in a number of other tumors, including gastrointestinal stromal tumors [21], renal cell tumors [22], childhood T-cell acute leukemia, pheochromocytoma and neuroblastomas [23]. Among all the $S D H$ mutations, a high frequency of $S D H$ germline mutations was identified in malignant extra-adrenal paragangliomas, and these mutations were associated with poor prognosis [24-26]. These studies suggest that $S D H$ mutations offer a strong advantage for cancer cell proliferation. So far, there have been more than 650 reported cases of $S D H$ mutations. In three cases of paragangliomatosis (HPGL) with $S D H$ mutation, succinate accumulated to a high level of 364-517 $\mu \mathrm{mol} \mathrm{g}{ }^{-1}$ protein [27]. More recently, it was reported that either depleting $S D H$ in mice or ectopic expression of tumor-derived SDH mutants resulted in the accumulation of succinate [28].

\subsection{Mutations of $\boldsymbol{F H}$ genes in cancer cause the accu- mulation of fumarate}

Fumarate hydratase $(\mathrm{FH})$ is the enzyme next to $\mathrm{SDH}$ in the TCA cycle, and catalyzes the reversible hydration/dehydration of fumarate to malate. The human genome contains only one FH gene, which encodes two different forms of fumarate hydratase. The longer form localized in mitochondrion participates in the TCA cycle, and the short form localized in the cytoplasm is involved in the urea cycle and purine synthesis. Mutations in $\mathrm{FH}$ gene were first identified in inherited uterine fibroids, skin leiomyoma and papillary renal cell cancer by a combination of mapping methods [29]. FH mutations were also found in cerebral cavernomas [30], Leydig cell tumors [31] and ovarian mucinous cystadenoma with low frequency [32]. So far, $F H$ mutations have been found in more than 300 cases. As with $S D H$ mutations, $F H$ mutations resulted in the accumulation of fumarate to a level as high as 417-688 $\mu \mathrm{mol} / \mathrm{g}$ protein in hereditary leiomyomatosis and renal cell cancer [27]. The accumulation of fumarate was also observed in cells depleted for $F H$ or expressing a tumor-derived FH mutant [28].

\subsection{IDH1 and IDH2 are most frequently mutated metabolic genes in human cancers}

IDH catalyzes the oxidative decarboxylation of isocitrate to produce $\alpha-K G$. The IDH family includes three different isoforms: IDH1, IDH2 and IDH3. IDH1 is located in the cytosol and peroxisomes, while IDH2 and IDH3 are located in mitochondria. IDH1 and IDH2 use $\mathrm{NADP}^{+}$as a cofactor, while IDH3 uses $\mathrm{NAD}^{+}$as a cofactor in the TCA cycle for energy metabolism [33].

The IDHI mutation was first found in human glioblastoma multiforme by a cancer genome project in 2008 [34]. A short time later, another cancer genome project identified a mutation in the $I D H I$ gene in leukemic cells from an acute 
myeloid leukemia (AML) patient compared with his normal skin cells [35]. These two findings were quickly confirmed by multiple groups through direct sequencing of $I D H I$ and its homologue $I D H 2$. Mutations in $I D H 1$ and $I D H 2$ were found in $75 \%$ of grade 2 to 3 gliomas and secondary glioblastoma, and in about $20 \%$ of AML [36-48]. Following the discovery in glioma and AML, IDHI and IDH2 mutations were also found in several other human tumors, including cartilaginous tumors (75\%) [49-51], intrahepatic cholangiocarcinoma (10\%) [52,53], thyroid carcinomas (16\%) [54,55], and less frequently in prostate cancer, acute B-lymphoblastic leukemia, paragangliomas, colorectal carcinoma, and melanoma [52,56,57]. Thus, IDH1 and IDH2 represent the most frequently mutated metabolic genes in human cancer (Table 1).

The mutations of $I D H 1$ and $I D H 2$ in different types of human tumors share four unique biochemical features. First, $I D H 1$ and $I D H 2$ mutations are all heterozygous and there is no loss of heterozygosis of the wild-type copy. This is consistent with both a gain of function and dominant effect over the remaining wild-type allele. Second, nearly all $I D H I$ and IDH2 mutations predominantly target a single amino acid residue, Arg132 in IDH1 (to one of six amino acid residues: His, Cys, Leu, Ile, Ser, Gly, or Val), or the corresponding $\operatorname{Arg} 172$ in IDH2 (to one of four different residues: Lys, Met, Gly, and Trp), and Arg140 in IDH2 (to either Gln or Trp). Moreover, these three residues are located in the active sites of the enzymes, suggesting a direct impact of the mutations on the enzyme catalytic activity. Two additional mutations targeting IDH1, R100A and G98D, was also found to occur less frequently in adult glioma and in a colon cancer cell line [58]. Third, all $I D H 1$ and $I D H 2$ mutations in human tumors are found to be somatic mutations, with germline mutations rarely observed. Finally, IDH1 and IDH2 mutations occur in a mutually exclusive manner in most cases, and few tumors have been found to harbor mutations in both IDHI and IDH 2 genes [38]. This fact suggests that mutations targeting $I D H I$ and $I D H 2$ share a common underlying biochemical mechanism.

\subsection{Mutant IDH1 and IDH2 lose their normal activity to produce $\alpha-K G$ and gain a new activity of producing D-2-HG}

Shortly after the first IDH1 mutation was reported, it was found that tumor-derived IDH1 mutants lost their normal activity to produce $\alpha-K G$. This functional inactivation led to a decrease of $\alpha-K G$ and increase of HIF1a protein levels, possibly because of the inhibition of prolyl hydroxylase (PHD) [59]. Thus, loss of the normal function of producing $\alpha-K G$ is the first biochemical alteration of tumor-derived IDH1 and IDH2 mutants.

A subsequent study using metabolite profiling surprisingly found that the IDH1 mutant not only loses its normal activity in the production of $\alpha-K G$, but also gains a new function: catalyzing the NADPH-dependent reduction of $\alpha-\mathrm{KG}$ to D-2-hydroxyglutarate (D-2-HG, also known as $R-2-\mathrm{HG})$ [60]. Further studies showed that all the tumor-derived mutants targeting three hot spots, Arg132 in IDH1 and Arg140 and Arg172 in IDH2, also gain this new activity [61-63]. In human glioma with IDH1/2 mutation, the level of D-2-HG accumulates as high as 5-35 $\mu \mathrm{mol} \mathrm{g}^{-1}$ (or 5-35 mmol L ${ }^{-1}$ ) [42]. In addition to glioma, D-2-HG accumulation has also been found in AML and enchondroma [50]. Taking advantage of such high D-2-HG levels, efforts

Table 1 Mutation of eight metabolic genes

\begin{tabular}{|c|c|c|c|c|}
\hline Enzyme & Gene & Catalytic reaction & Tumor types & Mutation frequency \\
\hline \multirow{5}{*}{$\begin{array}{l}\text { IDH1 (isocitrate } \\
\text { dehydrogenase 1) }\end{array}$} & \multirow{5}{*}{$I D H 1$} & \multirow{9}{*}{$\begin{array}{l}\text { Isocitrate+NADP }{ }^{+} \rightarrow \\
\alpha-\mathrm{KG}+\mathrm{NADPH}+\mathrm{CO}_{2}\end{array}$} & Glioma & $\sim 75 \%$ \\
\hline & & & AML & $20 \%$ \\
\hline & & & Enchondroma & $84 \%$ \\
\hline & & & Chondrosarcoma & $56 \%$ \\
\hline & & & Thyroid carcinomas & $17 \%$ \\
\hline \multirow{4}{*}{$\begin{array}{l}\text { IDH2 (isocitrate } \\
\text { dehydrogenase } 2 \text { ) }\end{array}$} & \multirow{4}{*}{$I D H 2$} & & Cholangiocarcinoma & $10 \%$ \\
\hline & & & B-cell ALL & $1 / 60$ \\
\hline & & & Paragangliomas & $1 / 131$ \\
\hline & & & Colorectal carcinoma & $2 / 180$ \\
\hline \multirow{4}{*}{$\begin{array}{l}\text { SDH (succinate } \\
\text { dehydrogenase) }\end{array}$} & SDHA & \multirow{4}{*}{$\begin{array}{l}\text { Succinate+ubiquinone } \rightarrow \\
\text { fumarate+ubiquinol }\end{array}$} & Parganglioma & $6 / 36$ \\
\hline & $S D H B$ & & Merkel cell carcinoma & $2 / 18$ \\
\hline & $S D H C$ & & Phaeochromocytoma & $5 / 22$ \\
\hline & $S D H A F 2$ & & Midgut carcinoid & $2 / 18$ \\
\hline \multirow{4}{*}{$\begin{array}{l}\text { FH (fumarate } \\
\text { hydatase) }\end{array}$} & \multirow{4}{*}{$F H$} & \multirow{4}{*}{ Fumarate $+\mathrm{H}_{2} \mathrm{O} \rightarrow$ malate } & Rebal cell carcinoma & $1 / 3$ \\
\hline & & & Lung adenocaicinoma & $1.1 \%$ \\
\hline & & & Melanoma & $1 / 14$ \\
\hline & & & Leiomyoma & $1.3 \%$ \\
\hline
\end{tabular}


have been made to noninvasively detect the accumulation of D-2-HG in glioma patients by magnetic resonance spectroscopy techniques for tumor diagnosis and imaging [64, 65].

\section{The mechanism of tumorigenesis linked to $\mathrm{SDH}, \mathrm{FH}$ and $I D H$ mutations}

\section{1 $\alpha$-KG dependent dioxygenases are a large family of enzymes involved in diverse cellular processes}

One emerging mechanism common to the tumorigenesis linked to mutations in all four metabolic enzymes is that they all lead to impaired activity of a family of enzymes collectively known as $\alpha$-KG-dependent dioxygenases. In 1967, Hutton et al. [66] identified the first $\alpha-K G$-dependent dioxygenase, which was named collagen prolyl hydroxylase $(\mathrm{CPH})$. After this pioneering work, the $\alpha-\mathrm{KG}$-dependent dioxygenases have been established as a widely distributed family. Sequence homology analysis suggests that there are more than 60 members in humans $[67,68]$. The $\alpha-K G$ dependent dioxygenases catalyze the hydroxylation reactions with diverse substrates, including collagen, histones, transcription factors, alkylated DNA and RNA, lipids, antibiotics, and the recently discovered 5-methylcytosine of genomic DNA and 6-methyladenine of RNA $[69,70]$. In recent years, the biological roles of $\alpha-K G$-dependent dioxygenases have been expanded to multiple pathways, such as CPHs in collagen stabilization and endostatin production, trimethyllysine hydroxylase in fatty acid metabolism, prolyl hydroxylases (PHDs) and factor inhibiting-HIF (FIH) in hypoxic signaling, AlkB homologs in DNA and RNA repair, histone lysine demethylases (KDMs) and DNA hydroxylases of ten-eleven translocases (TETs) for epigenetic regulation on histones and DNA (Table 2).

$\alpha-\mathrm{KG}$ plays critical roles in multiple cellular metabolic pathways, such as TCA cycle, anaplerosis, amino acid and fatty acid synthesis, and hydroxylation of proteins and nucleic acids. In the hydroxylation reaction, $\alpha-K G$ serves as a co-substrate for all $\alpha-K G-d e p e n d e n t$ dioxygenases [70], which use both atoms of molecular oxygen for substrate hydroxylation. Both $\alpha-\mathrm{KG}$ and $\mathrm{O}_{2}$ are considered to be cosubstrates, with one oxygen atom attached to a hydroxyl group in the substrate (hydroxylation) and the other one taken up by $\alpha-K G$, leading to the decarboxylation of $\alpha-K G$ and formation of carbon dioxide and succinate. All $\alpha-\mathrm{KG}-$ dependent dioxygenases require $\mathrm{Fe}(\mathrm{II})$ as a cofactor. The last role of $\alpha-\mathrm{KG}$ in supporting the $\alpha$-KG-dependent dioxygenases appear to be impaired in cells with mutation targeting any of four metabolic enzymes.

\subsection{SDH and FH mutants inhibit multiple $\alpha$-KG de- pendent dioxygenases}

In 1977, Raili et al. [71] found that succinate was a competitive inhibitor of $\alpha-\mathrm{KG}$ and could suppress $\mathrm{CPH}$, an $\alpha-\mathrm{KG}$ dependent dioxygenase involved in collagen biosynthesis. Several years after the $S D H$ mutation was reported, it was shown that the elevated level of succinate in cells caused by the inhibition of $S D H$ could lead to the inhibition of PHDs, resulting in accumulation of both HIF- $1 \alpha$ and HIF-2 $\alpha$ [27]. This unveiled the first biochemical mechanism linking succinate to tumorigenesis. Another study further provided in vivo evidence for this model. Elevated levels of succinate and fumarate caused by $S D H$ mutations in paragangliomas and $F H$ mutations in renal cell cancer, respectively, lead to the accumulation of HIF-1 $\alpha$ through the inhibition of PHD [27]. As expected, elevated HIF-1 $\alpha$ is also observed in cells

Table $2 \alpha-K G$ dependent dioxygenases and their substrates

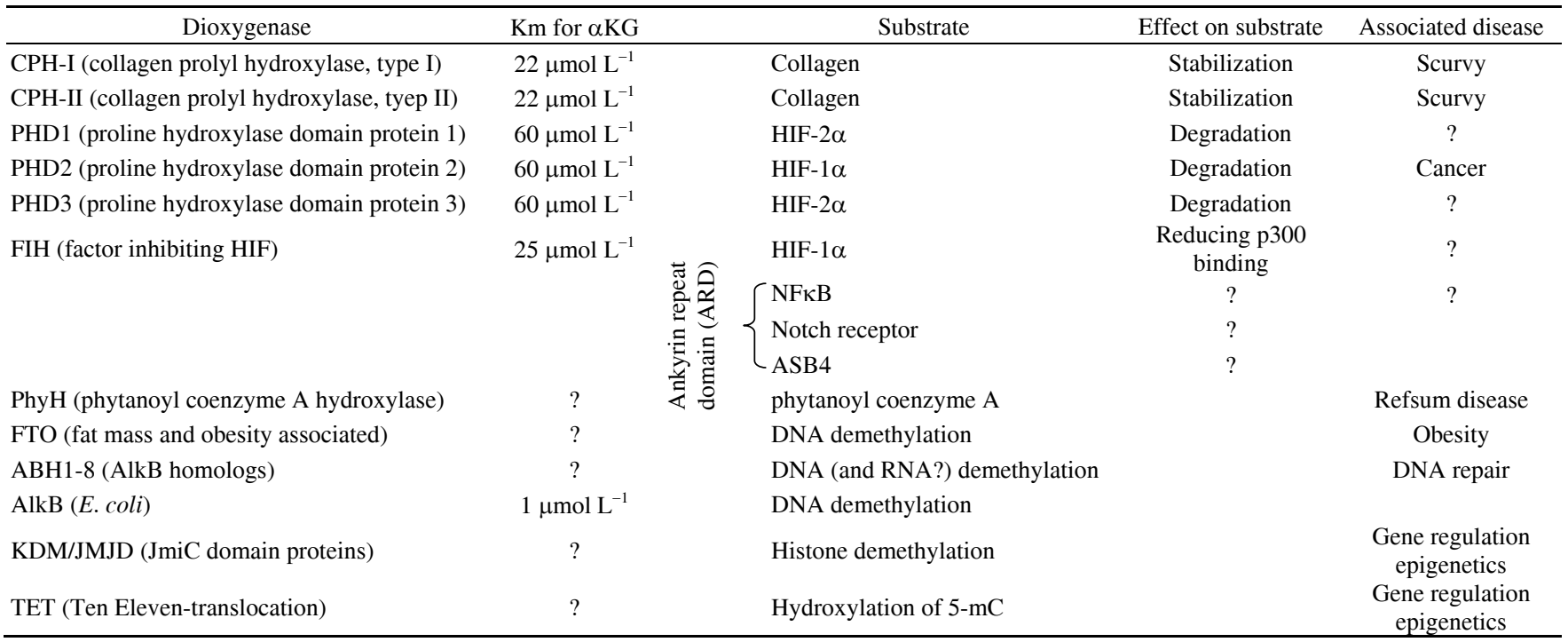


with mutations of SDH or FH.

The KDMs and TET DNA hydroxylases are two sub-families of $\alpha$-KG-dependent dioxygenases that control the epigenetic modifications in the cells. A recent study showed that both succinate and fumarate inhibit KDM from human and $C$. elegans. The $\mathrm{IC}_{50}$ of succinate and fumarate of human KDM4A are 0.8 and $1.5 \mathrm{mmol} \mathrm{L}^{-1}$, respectively [28]. Knocking down $S D H$ or $F H$ or overexpression of the tumor-derived SDH or FH mutant significantly increased genome-wide histone and DNA methylation [28]. Furthermore, two DNA methylation profiling studies found that $S D H$ mutations in gastrointestinal stromal tumors, paragangliomas and pheochromocytomas were associated with genomic hypermethylation [72,73]. In addition, decreased levels of 5-hydroxymethylcytosine were associated with SDH mutations in gastrointestinal stromal tumors [74]. Taken together, the in vivo evidence strongly supports that mutation in $\mathrm{FH}$ or $\mathrm{SDH}$ results in global genome changes in DNA methylation, likely due to inhibition of TET proteins by fumarate or succinate, thus leading to epigenetic alterations in cancers. These studies raise an exciting possibility of treating cancers by interfering with epigenetic pathways.

\subsection{IDH mutants inhibit $\alpha$-KG-dependent histone and DNA demethylases}

The oncometabolite of D-2-HG, produced by IDH mutants, acts as an antagonist of $\alpha-K G$ to inhibit multiple $\alpha-K G$ dependent dioxygenases. However, not all $\alpha-K G$ dependent dioxygenases are equally inhibited by D-2-HG. A systematic in vitro enzymatic study showed that the histone H3K9/H3K36 demethylases KDM4A/JMJD2A and KDM4C/ JMJD4C are most sensitive to a low $\mathrm{IC}_{50}$ of 24 and $79 \mu \mathrm{mol}$ $\mathrm{L}^{-1}$, respectively [75]. Three in vivo studies confirmed this finding in cultured cells, human tumor samples, and mouse models. First, elevated levels of multiple histone methylation markers were observed in cells expressing tumorderived IDH1/2 mutants and gliomas with an $I D H 1^{R I 32 H}$ mutation [63]. Second, IDH mutation is associated with a block to differentiation and repression of lineage-specific differentiation genes through the inhibition of KDM4C [76]. Third, increased levels of histone methylation markers, including trimethyl H3K4, H3K9, H3K27, and H3K36 and dimethyl H3K79, are observed in $I D H 1^{R 132 H}$ knock-in cells [77] and an $I D H 1^{R 132 H}$ conditional knock-in mouse model [78].

The TET family of DNA hydroxylases catalyzes three sequential oxidative reactions, first converting 5-methylcytosine $(5 \mathrm{mC})$ to 5 -hydroxylcytosine $(5 \mathrm{hmC})$, then to 5-formaylcytosine (5fC), and finally to 5-carboxylcytosine (5caC), leading to DNA demethylation [79-83]. D-2-HG directly inhibits TET activity in vitro, and the expression of tumor-derived IDH1 or IDH2 mutants also inhibits TETinduced $5 \mathrm{mC}$ hydroxylation in transfected cells $[61,63]$.
Importantly, genetic evidence supports TET DNA hydroxylase as the major target of IDH1/2 mutations. First, a promoter methylation analysis study demonstrated that a subset of glioblastoma, a proneural subgroup that is tightly associated with IDH1 mutations, shows a distinct $\mathrm{CpG}$ island methylation phenotype (G-CIMP) [84]. A similar DNA hypermethylation phenotype is observed in AML with IDHI/2 mutation [61]. Recently, two genetic models, IDH1(R132H/WT) knock-in cells and mice, also showed global DNA hypermethylation [77,78]. These findings suggest a causal link between $I D H 1 / 2$ mutation and elevated DNA methylation. Second, mutations of TET2 occur in a mutually exclusive manner with $I D H 1 / 2$ mutations, indicating a common pathogenesis caused by mutation in TET2 or IDHI/2 in AML [61]. Third, stable expression of an IDH1 mutant in primary human astrocytes induces extensive DNA hypermethylation and reshapes the methylome in a fashion that mirrors the changes observed in G-CIMP-positive lower-grade gliomas that have frequent IDH mutations [85]. Collectively, these studies establish a model in which TET hydroxylases are the major targets of $I D H 1 / 2$ mutations to promote tumorigenesis.

\subsection{Succinate, fumarate and D-2-HG are structurally similar to and act as antagonists of $\alpha-K G$}

Structural studies have revealed a conserved coordination between $\alpha$-KG-dependent dioxygenases and their cofactor and cosubstrate. In the catalytic core of $\alpha$-KG-dependent dioxygenases, $\alpha-\mathrm{KG}$ uses two oxygen atoms from the $\alpha$-keto carboxyl end, one from its $\mathrm{C}-1$ hydroxyl group and the other from its C-2 ketone group, to coordinate with $\mathrm{Fe}(\mathrm{II})$, and two other oxygen atoms from the acetate end to interact with conserved amino residues in the dioxygenases. Structural analysis shows that D-2-HG is similar to $\alpha-K G$ except for the oxidative state at the $\mathrm{C}-2$, whereby the ketone group is replaced by a hydroxyl group in D-2-HG (Figure 1). Likewise, both succinate and fumarate are structurally similar to $\alpha-K G$, with the exception that the ketone group at the $\mathrm{C}-2$ position in $\alpha-\mathrm{KG}$ is missing in succinate and fumarate (Figure 1). Thus, these structural similarities suggest that succinate, fumarate and D-2-HG may act as competitive inhibitors of $\alpha-K G$ to interfere with the function of $\alpha-K G$-dependent dioxygenases. This hypothesis was supported by a series of experiments both in vitro and in vivo [27,63,71-74,84]. Moreover, structural analyses have shown that succinate and fumarate could bind the $\alpha-K G-$ dependent dioxygenases in their catalytic core just like $\alpha-\mathrm{KG}$, such as FIH and AlkB [70,86]. Additionally, D-2-HG binds KDM7A in a configuration similar to $\alpha-K G$ [63]. Thus, these results provide direct evidence supporting succinate, fumarate, and D-2-HG as antagonists of $\alpha-\mathrm{KG}$ in the cell to inhibit $\alpha-\mathrm{KG}$-dependent dioxygenases. 


\section{Conclusion and perspectives}

During the past ten years, researchers have shown increasing interest in metabolism alterations in tumorigenesis, fueled in part by the discovery of metabolic gene mutations in cancer. Common metabolites not only can regulate enzyme activity through classical allosteric effects, but also influence multiple cellular processes through global effects, such as inhibition of the dioxygenase family. As discussed above, three oncometabolites, D-2-HG, succinate and fumarate, act as antagonists of $\alpha-\mathrm{KG}$ and inhibit a large number of $\alpha-K G$-dependent dioxygenases to control a diversity of cellular activities, including hypoxia response and<smiles>O=C(O)CCC(=O)O</smiles><smiles>O=C(O)CCC(O)C(=O)O</smiles><smiles></smiles>

epigenetics regulation (Figure 2). One may also speculate that many other metabolites serve as signaling molecules to influence whole cell and body physiology. Therefore, proteins/enzymes that are regulated by metabolites can be considered as cellular sensors for metabolic status, thereby functioning to coordinate global cellular activity/function with metabolic status.

The realization that metabolites can have global regulatory effects on cells not only significantly advances our understanding of the intricate regulatory network between small molecules (metabolites) and macromolecules (protein, RNA, and DNA), but also provides exciting leads for future therapeutic intervention for disease treatments. By nature, small molecules are much easier to be produced, optimized<smiles>O=C(O)C=CC(=O)O</smiles><smiles>O=C([O-])CCC(=O)O[Ga]1[CH]CC1</smiles><smiles>O=C([O-])C=CC(=O)O[Ga]1[C+]NC1</smiles>

Figure 1 Structural comparison of fumarate, succinate, $\alpha-\mathrm{KG}$, and D-2-HG. The oxygen in the ketone group at the C-2 position of $\alpha-\mathrm{KG}$ is responsible for the coordination of $\mathrm{Fe}(\mathrm{II})$ in $\alpha$-KG-dependent dioxygenase. All three oncometabolites, D-2-HG, fumarate and succinate, share structural similarity with $\alpha-\mathrm{KG}$, except for the oxidative state at the C-2 position. The 2-ketone group at the C-2 position in $\alpha$-KG is replaced by a hydroxyl group in D-2-HG and is absent in fumarate and succinate.

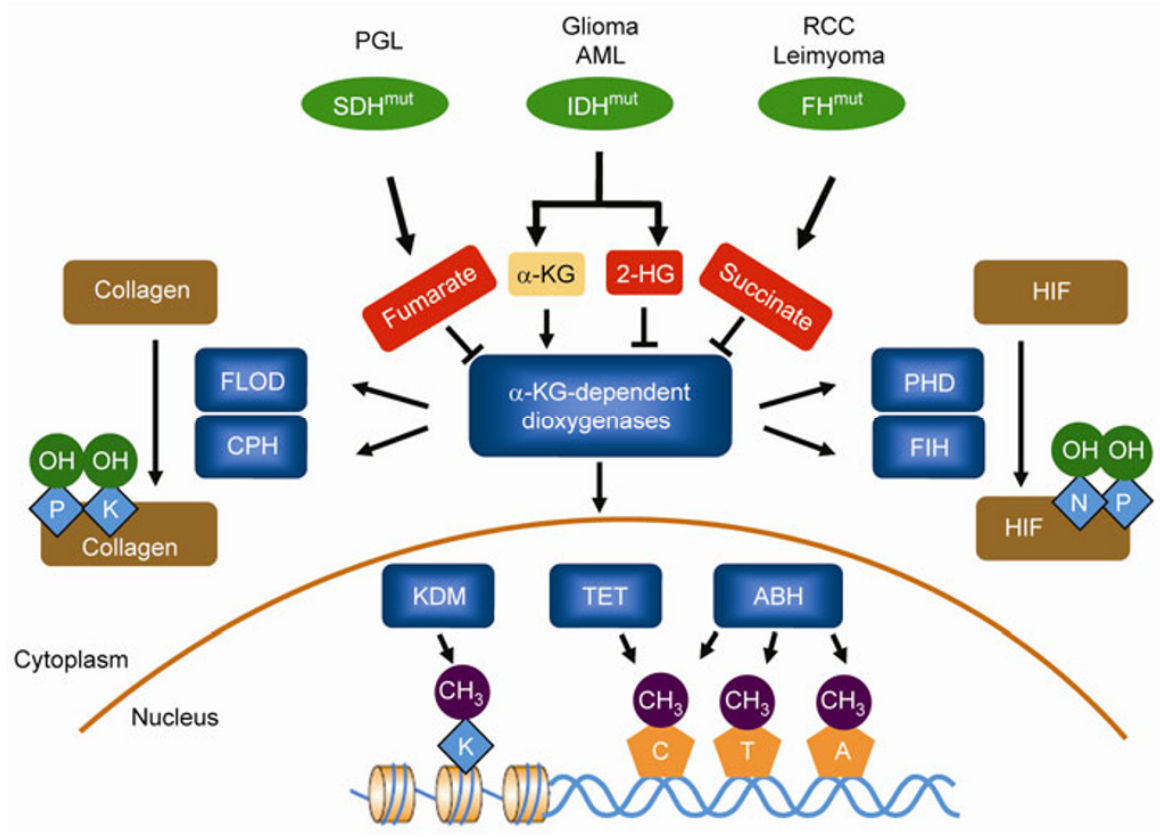

Figure $2 I D H 1 / 2$ mutations alter epigenetic regulation by inhibiting both histone and DNA demethylation. Mutations of $I D H 1 / 2, S D H$ and $F H$ lead to the accumulation of D-2-HG, fumarate and succinate, respectively, which can function as $\alpha$-KG antagonists to broadly inhibit $\alpha$-KG-dependent dioxygenases, including the JMJD family KDMs and the TET family of 5mC hydroxylases. PGL, paragangliomatosis; AML, acute myeloid leukemia; RCC, renal cell carcinoma. 
by modification, and delivered into the human body. The mechanistic understanding of metabolites in cellular regulation will facilitate the use of metabolites or their analogs for treatment of human disease.

1 Warburg O. On the origin of cancer cells. Science, 1956, 123: 309314

2 Warburg O. Über den stoffwechsel der carcinomzelle. J Mol Med, 1925, 4: 534-536

3 Avril N, Dose J, Jänicke F, et al. Metabolic characterization of breast tumors with positron emission tomography using f-18 fluorodeoxyglucose. J Clin Oncol, 1996, 14: 1848-1857

4 de Santis M, Becherer A, Bokemeyer C, et al. $2{ }^{18}$ fluoro-deoxyd-glucose positron emission tomography is a reliable predictor for viable tumor in postchemotherapy seminoma: An update of the prospective multicentric sempet trial. J Clin Oncol, 2004, 22: 10341039

5 Oermann E K, Wu J, Guan K L, et al. Alterations of metabolic genes and metabolites in cancer. Semin Cell Dev Biol, 2012, 23: 370-380

6 Hsu P P, Sabatini D M. Cancer cell metabolism: Warburg and beyond. Cell, 2008, 134: 703-707

7 Vander Heiden M G, Cantley L C, Thompson C B. Understanding the warburg effect: The metabolic requirements of cell proliferation. Sci Signal, 2009, 324: 1029

8 Wise D R, Thompson C B. Glutamine addiction: A new therapeutic target in cancer. Trends Biochem Sci, 2010, 35: 427-433

9 Daye D, Wellen K E. Metabolic reprogramming in cancer: Unraveling the role of glutamine in tumorigenesis. Semin Cell Dev Biol, 2012, 23: 362-369

10 Le A, Lane A N, Hamaker M, et al. Glucose-independent glutamine metabolism via TCA cycling for proliferation and survival in B cells. Cell Metab, 2012, 15: 110-121

11 Metallo C M, Gameiro P A, Bell E L, et al. Reductive glutamine metabolism by IDH1 mediates lipogenesis under hypoxia. Nature, 2011, 481: 380-384

12 Mullen A R, Wheaton W W, Jin E S, et al. Reductive carboxylation supports growth in tumour cells with defective mitochondria. Nature, 2011, 481: 385-388

13 Wise D R, Ward P S, Shay J E, et al. Hypoxia promotes isocitrate dehydrogenase-dependent carboxylation of $\alpha$-ketoglutarate to citrate to support cell growth and viability. Proc Natl Acad Sci USA, 2011, 108: 19611-19616

14 Fuchs B C, Bode B P. Amino acid transporters ASCT2 and LAT1 in cancer: Partners in crime? Semin Cancer Biol, 2005, 15: 254-266

15 Fuchs B C, Finger R E, Onan M C, et al. ASCT2 silencing regulates mammalian target-of-rapamycin growth and survival signaling in human hepatoma cells. Am J Physiol Cell Physiol, 2007, 293: C55C63

$16 \mathrm{Hu} \mathrm{W}$, Zhang $\mathrm{C}$, Wu R, et al. Glutaminase 2, a novel p53 target gene regulating energy metabolism and antioxidant function. Sci Signal, 2010, 107: 7455

17 Suzuki S, Tanaka T, Poyurovsky M V, et al. Phosphate-activated glutaminase (GLS2), a p53-inducible regulator of glutamine metabolism and reactive oxygen species. Sci Signal, 2010, 107: 7461

18 Hao H X, Khalimonchuk O, Schraders M, et al. SDH5, a gene required for flavination of succinate dehydrogenase, is mutated in paraganglioma. Science, 2009, 325: 1139-1142

19 Baysal B E, Ferrell R E, Willett-Brozick J E, et al. Mutations in SDHD, a mitochondrial complex II gene, in hereditary paraganglioma. Science, 2000, 287: 848-851

20 Gimm O, Armanios M, Dziema H, et al. Somatic and occult germline mutations in SDHD, a mitochondrial complex II gene, in nonfamilial pheochromocytoma. Cancer Res, 2000, 60: 6822-6825

21 McWhinney S R, Pasini B, Stratakis C A. Familial gastrointestinal stromal tumors and germ-line mutations. N Engl J Med, 2007, 357: 1054-1056

22 Ricketts C, Woodward E R, Killick P, et al. Germline SDHB mutations and familial renal cell carcinoma. J Nat Cancer Inst, 2008, 100: 1260-1262

23 Bardella C, Pollard P J, Tomlinson I. SDH mutations in cancer. Biochim Biophys Acta Bioenerg, 2011, 1807: 1432-1443

24 Timmers H J, Kozupa A, Eisenhofer G, et al. Clinical presentations, biochemical phenotypes, and genotype-phenotype correlations in patients with succinate dehydrogenase subunit B-associated pheochromocytomas and paragangliomas. J Clin Endocrinol Metab, 2007, 92: 779-786

25 Gimenez-Roqueplo A P, Favier J, Rustin P, et al. Mutations in the $S D H B$ gene are associated with extra-adrenal and/or malignant phaeochromocytomas. Cancer Res, 2003, 63: 5615-5621

26 Amar L, Baudin E, Burnichon N, et al. Succinate dehydrogenase B gene mutations predict survival in patients with malignant pheochromocytomas or paragangliomas. J Clin Endocrinol Metab, 2007, 92: 3822-3828

27 Pollard P, Briere J, Alam N, et al. Accumulation of Krebs cycle intermediates and over-expression of hif $1 \alpha$ in tumours which result from germline FH and SDH mutations. Hum Mol Genet, 2005, 14: 2231-2239

28 Xiao M, Yang $\mathrm{H}, \mathrm{Xu} \mathrm{W}$, et al. Inhibition of $\alpha$-kg-dependent histone and DNA demethylases by fumarate and succinate that are accumulated in mutations of FH and SDH tumor suppressors. Genes Dev, 2012, 26: 1326-1338

29 Tomlinson I P, Alam N A, Rowan A J, et al. Germline mutations in FH predispose to dominantly inherited uterine fibroids, skin leiomyomata and papillary renal cell cancer. Nat Genet, 2002, 30: 406-410

30 Campione E, Terrinoni A, Orlandi A, et al. Cerebral cavernomas in a family with multiple cutaneous and uterine leiomyomas associated with a new mutation in the fumarate hydratase gene. J Invest Dermatol, 2007, 127: 2271-2273

31 Carvajal-Carmona L G, Alam N A, Pollard P J, et al. Adult leydig cell tumors of the testis caused by germline fumarate hydratase mutations. J Clin Endocrinol Metab, 2006, 91: 3071-3075

32 Ylisaukko-oja S K, Cybulski C, Lehtonen R, et al. Germline fumarate hydratase mutations in patients with ovarian mucinous cystadenoma. Eur J Hum Genet, 2006, 14: 880-883

33 Yang H, Ye D, Guan K L, et al. IDH1 and IDH2 mutations in tumorigenesis: Mechanistic insights and clinical perspectives. Clin Cancer Res, 2012, 18: 5562-5571

34 Parsons D W, Jones S, Zhang X, et al. An integrated genomic analysis of human glioblastoma multiforme. Science, 2008, 321: 1807-1812

35 Mardis E R, Ding L, Dooling D J, et al. Recurring mutations found by sequencing an acute myeloid leukemia genome. N Engl J Med, 2009, 361: 1058-1066

36 Balss J, Meyer J, Mueller W, et al. Analysis of the IDH1 codon 132 mutation in brain tumors. Acta Neuropathol, 2008, 116: 597-602

37 Bleeker F E, Lamba S, Leenstra S, et al. IDH1 mutations at residue p.R132 (idh1r132) occur frequently in high-grade gliomas but not in other solid tumors. Hum Mutat, 2009, 30: 7-11

38 Hartmann C, Meyer J, Balss J, et al. Type and frequency of IDH1 and IDH2 mutations are related to astrocytic and oligodendroglial differentiation and age: A study of 1010 diffuse gliomas. Acta Neuropathol, 2009, 118: 469-474

39 Watanabe T, Nobusawa S, Kleihues P, et al. IDH1 mutations are early events in the development of astrocytomas and oligodendrogliomas. Am J Pathol, 2009, 174: 1149-1153

40 Yan H, Parsons D W, Jin G, et al. IDH1 and IDH2 mutations in gliomas. N Engl J Med, 2009, 360: 765-773

41 Chou W C, Hou H A, Chen C Y, et al. Distinct clinical and biologic characteristics in adult acute myeloid leukemia bearing the isocitrate dehydrogenase 1 mutation. Blood, 2010, 115: 2749-2754

42 Dang L, Jin S, Su S M. IDH mutations in glioma and acute myeloid leukemia. Trends Mol Med, 2010, 16: 387-397

43 Gravendeel L A M, Kloosterhof N K, Bralten L B C, et al. Segregation of non-p.R132h mutations in IDH1 in distinct molecular subtypes of glioma. Hum Mutat, 2010, 31: E1186-E1199 
44 Gross S, Cairns R A, Minden M D, et al. Cancer-associated metabolite 2-hydroxyglutarate accumulates in acute myelogenous leukemia with isocitrate dehydrogenase 1 and 2 mutations. J Exp Med, 2010, 207: 339-344

45 Ho P A, Alonzo T A, Kopecky K J, et al. Molecular alterations of the IDH1 gene in AML: A children's oncology group and southwest oncology group study. Leukemia, 2010, 24: 909-913

46 Tefferi A, Lasho T L, Abdel-Wahab O, et al. IDH1 and IDH2 mutation studies in 1473 patients with chronic-, fibrotic- or blast-phase essential thrombocythemia, polycythemia vera or myelofibrosis. Leukemia, 2010, 24: 1302-1309

47 Wagner K, Damm F, Gohring G, et al. Impact of IDH1 R132 mutations and an IDH1 single nucleotide polymorphism in cytogenetically normal acute myeloid leukemia: SNP rs11554137 is an adverse prognostic factor. J Clin Oncol, 2010, 28: 2356-2364

48 Ward P S, Patel J, Wise D R, et al. The common feature of leukemiaassociated IDH1 and IDH2 mutations is a neomorphic enzyme activity converting $\alpha$-ketoglutarate to 2-hydroxyglutarate. Cancer Cell, 2010, 17: 225-234

49 Amary M F, Bacsi K, Maggiani F, et al. IDH1 and IDH2 mutations are frequent events in central chondrosarcoma and central and periosteal chondromas but not in other mesenchymal tumours. J Pathol, 2011, 224: 334-343

50 Amary M F, Damato S, Halai D, et al. Ollier disease and maffucci syndrome are caused by somatic mosaic mutations of IDH1 and IDH2. Nat Genet, 2011, 43: 1262-1265

51 Pansuriya T C, van Eijk R, d'Adamo P, et al. Somatic mosaic IDH1 and IDH2 mutations are associated with enchondroma and spindle cell hemangioma in ollier disease and maffucci syndrome. Nat Genet, 2011, 43: 1256-1261

52 Borger D R, Tanabe K K, Fan K C, et al. Frequent mutation of isocitrate dehydrogenase (IDH) 1 and IDH2 in cholangiocarcinoma identified through broad-based tumor genotyping. Oncologist, 2011, 17: 72-79

53 Wang P, Dong Q, Zhang C, et al. Mutations in isocitrate dehydrogenase 1 and 2 occur frequently in intrahepatic cholangiocarcinomas and share hypermethylation targets with glioblastomas. Oncogene, 2013, 32: 3091-3100

54 Hemerly J P, Bastos A U, Cerutti J M. Identification of several novel non-p.R132 IDH1 variants in thyroid carcinomas. Eur J Endocrinol, 2010, 163: 747-755

55 Murugan A K, Bojdani E, Xing M. Identification and functional characterization of isocitrate dehydrogenase 1 (IDH1) mutations in thyroid cancer. Biochem Biophys Res Commun, 2010, 393: 555-559

56 Kang M R, Kim M S, Oh J E, et al. Mutational analysis of IDH1 codon 132 in glioblastomas and other common cancers. Int J Cancer, 2009, 125: 353-355

57 Gaal J, Burnichon N, Korpershoek E, et al. Isocitrate dehydrogenase mutations are rare in pheochromocytomas and paragangliomas. J Clin Endocrinol Metab, 2010, 95: 1274-1278

58 Pusch S S F, Meyer J, Mittelbronn M, et al. Glioma IDH1 mutation patterns off the beaten track. Neuropathol Appl Neurobiol, 2011, 37: $428-430$

59 Zhao $\mathrm{S}$, Lin $\mathrm{Y}, \mathrm{Xu} \mathrm{W}$, et al. Glioma-derived mutations in IDH1 dominantly inhibit IDH1 catalytic activity and induce HIF-1 $\alpha$. Science's STKE, 2009, 324: 261

60 Dang L, White D W, Gross S, et al. Cancer-associated IDH1 mutations produce 2-hydroxyglutarate. Nature, 2009, 462: 739-744

61 Figueroa M E, Abdel-Wahab O, Lu C, et al. Leukemic IDH1 and IDH2 mutations result in a hypermethylation phenotype, disrupt TET2 function, and impair hematopoietic differentiation. Cancer Cell, 2010, 18: 553-567

62 Ward P, Cross J, Lu C, et al. Identification of additional IDH mutations associated with oncometabolite $\mathrm{R}(-)$-2-hydroxyglutarate production. Oncogene, 2012, 31: 2491-2498

$63 \mathrm{Xu} \mathrm{W}$, Yang H, Liu Y, et al. Oncometabolite 2-hydroxyglutarate is a competitive inhibitor of $\alpha$-ketoglutarate-dependent dioxygenases. Cancer Cell, 2011, 19: 17-30
64 Jalbert L, Elkhaled A, Phillips J, et al. Presence of 2-hydroxyglutarate in IDH1 mutated low-grade glioma using ex vivo proton hr-mas spectroscopy. Proc Intl Soc Mag Reson Med, 2011, 19: 183

65 Kalinina J C A, Wang L, Yu Q, et al. Detection of "oncometabolite" 2-hydroxyglutarate by magnetic resonance analysis as a biomarker of IDH1/2 mutations in glioma. J Mol Med (Berl), 2012, 90: 1161-1171

66 Hutton Jr J J, Kaplan A, Udenfriend S. Conversion of the amino acid sequence gly-pro-pro in protein to gly-pro-hyp by collagen proline hydroxylase. Arch Biochem Biophys, 1967, 121: 384-391

67 Rose N R, McDonough M A, King O N F, et al. Inhibition of 2-oxoglutarate dependent oxygenases. Chem Soc Rev, 2011, 40: 4364

68 Pollard P, Loenarz C, Mole D, et al. Regulation of Jumonji-domaincontaining histone demethylases by hypoxia-inducible factor (HIF)1alpha. Biochem J, 2008, 416: 387-394

69 Hausinger R P. FeII/alpha-ketoglutarate-dependent hydroxylases and related enzymes. Crit Rev Biochem Mol Biol, 2004, 39: 21-68

70 Loenarz C, Schofield C J. Expanding chemical biology of 2-oxoglutarate oxygenases. Nat Chem Biol, 2008, 4: 152-156

71 Tuderman L, Myllylä R, Kivirikko K I. Mechanism of the prolyl hydroxylase reaction. Eur J Biochem, 1977, 80: 341-348

72 Letouzé E, Martinelli C, Loriot C, et al. SDH mutations establish a hypermethylator phenotype in paraganglioma. Cancer Cell, 2013, 23: 739-752

73 Killian J K, Kim S Y, Miettinen M, et al. Succinate dehydrogenase mutation underlies global epigenomic divergence in gastrointestinal stromal tumor. Cancer Discovery, 2013, 3: 648-657

74 Mason E F, Hornick J L. Succinate dehydrogenase deficiency is associated with decreased 5-hydroxymethylcytosine production in gastrointestinal stromal tumors: Implications for mechanisms of tumorigenesis. Modern Pathol, 2013, doi: 10.1038/modpathol.2013.86

75 Chowdhury R, Yeoh K K, Tian Y M, et al. The oncometabolite 2-hydroxyglutarate inhibits histone lysine demethylases. EMBO Rep, 2011, 12: 463-469

76 Lu C, Ward P S, Kapoor G S, et al. IDH mutation impairs histone demethylation and results in a block to cell differentiation. Nature, 2012, 483: 474-478

77 Duncan C G, Barwick B G, Jin G, et al. A heterozygous IDH1R132H/WT mutation induces genome-wide alterations in DNA methylation. Genome Res, 2012, 22: 2339-2355

78 Sasaki M, Knobbe C B, Munger J C, et al. IDH1 (R132H) mutation increases murine haematopoietic progenitors and alters epigenetics. Nature, 2012, 488: 656-659

79 Kriaucionis S, Heintz N. The nuclear DNA base 5-hydroxymethylcytosine is present in purkinje neurons and the brain. Science, 2009, 324: 929-930

80 Tahiliani M, Koh K P, Shen Y, et al. Conversion of 5-methylcytosine to 5-hydroxymethylcytosine in mammalian DNA by mll partner TET1. Science, 2009, 324: 930-935

81 Ito S, D'Alessio A C, Taranova O V, et al. Role of Tet proteins in $5 \mathrm{mC}$ to $5 \mathrm{hmC}$ conversion, ES-cell self-renewal and inner cell mass specification. Nature, 2010, 466: 1129-1133

82 He Y F, Li B Z, Li Z, et al. Tet-mediated formation of 5-carboxylcytosine and its excision by TDG in mammalian DNA. Science, 2011, 333: 1303-1307

83 Ito S, Shen L, Dai Q, et al. Tet proteins can convert 5-methylcytosine to 5-formylcytosine and 5-carboxylcytosine. Science, 2011, 333: 1300-1303

84 Noushmehr H, Weisenberger D J, Diefes K, et al. Identification of a CPG island methylator phenotype that defines a distinct subgroup of glioma. Cancer Cell, 2010, 17: 510-522

85 Turcan S, Rohle D, Goenka A, et al. IDH1 mutation is sufficient to establish the glioma hypermethylator phenotype. Nature, 2012, 483: 479-483

86 Hewitson K S, Liénard B M, McDonough M A, et al. Structural and mechanistic studies on the inhibition of the hypoxia-inducible transcription factor hydroxylases by tricarboxylic acid cycle intermediates. J Biol Chem, 2007, 282: 3293-3301 


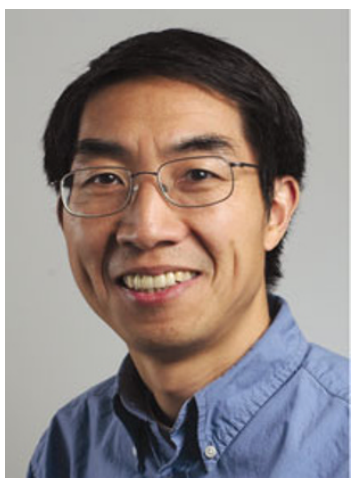

\section{Biographical Sketch}

Dr. Guan KunLiang is a professor at the Department of Pharmacology, University of California San Diego (2007-present). He received his B.S. degree (1982) from Hangzhou University, China. As a fellow of the second class of CUSBEA, he attended Purdue University and received both his Ph.D. (1989) and postdoctoral training at Purdue University. Dr. Guan started as an assistant Professor at the University of Michigan (1992) and was promoted to full Professor in 2000. He was later appointed as the Halvor Christensen Professor (2003) at the University of Michigan. He received the MacArthur Fellowship (1998), Scherling-Plaugh Award (1999), and Distinguished Alumni Award (2006) at Purdue University, and was elected to Fellow of AAAS (2011). Dr. Guan studies signaling mechanisms of organ size control and tumorigenesis, with particular focus on the mTOR and Hippo pathways.

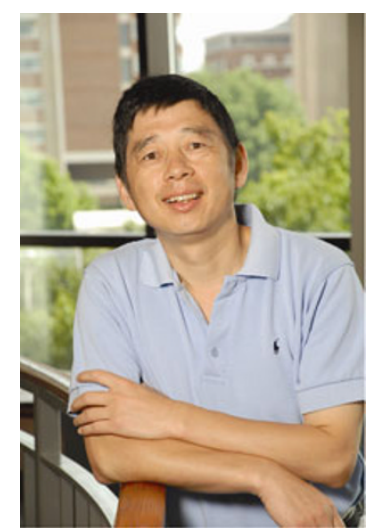

Dr. Xiong Yue is currently the William. R. Kenan Professor at the Lineberger Comprehensive Cancer Center in University of North Carolina at Chapel Hill. He obtained his B.S. degree in molecular biology from Fudan University in 1982. As a fellow of the CUSBEA class, he joined the University of Rochester as a predoctoral student and then began his postdoctoral training in Dr. David Beach's lab at Cold Spring Harbor Laboratory. Dr. Xiong started his own lab in the University of North Carolina at Chapel Hill in 1993. His research mainly focuses on the mechanisms of cell proliferation and tumorigenesis. In 2006, Dr. Xiong Yue together with Dr. Guan KunLiang started the Molecular Cell Biology (MCB) lab in Fudan University to study metabolism alterations in human diseases. Dr. Xiong received the Pew Scholar in the Biomedical Sciences (1995), AACR Gertrude B. Elion Cancer Research Award (1999) and was elected as an AAAS fellow (2011).

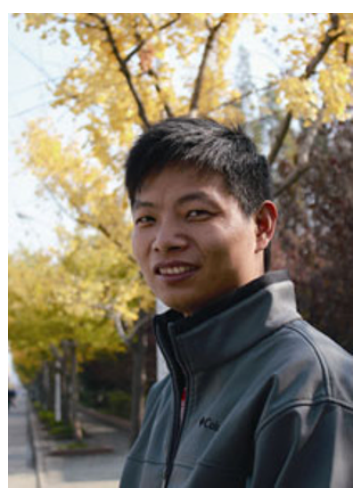

Dr. Yang Hui is a doctoral student at Fudan University and is supervised by Drs. Xiong and Guan. He graduated from Huazhong University of Science and Technology in 2008 and joined the MCB lab at Fudan University. Dr. Yang's Ph.D. research mainly focuses on the dynamic regulation of epigenetic modifications by metabolites. He received the Ray Wu Prize in 2012.

Open Access This article is distributed under the terms of the Creative Commons Attribution License which permits any use, distribution, and reproduction in any medium, provided the original author(s) and source are credited. 